\section{Military Technical College Kobry El-Kobbah, Cairo, Egypt.}

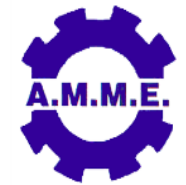

\title{
THERMOPHYSICAL PROPERTIES ENHANCEMENT FOR COPPER- POLYANILINE NANOFLUID SYNTHESIZED BY GAMMA RADIOLYSIS METHOD
}

\author{
S. Abdel-Samad ${ }^{1, *}$, A. Alyan ${ }^{2}$, A. Massoud ${ }^{1}$, S. A. Waly ${ }^{3}$
}

\begin{abstract}
In this study, Copper-Polyaniline nanocomposite (Cu-PAni) has been synthesized by gamma radiolysis as a novel method and was confirmed by different analytical techniques such as Scanning Electron Microscope (SEM), Transmission Electron Microscope (TEM), X-ray powder diffraction (XRD).. The thermal conductivity of the nanofluids has been measured at different nanofluids volume fractions of $0.2 \%$, $0.4 \%, 0.6 \%, 0.8 \%$ and $1.0 \%$. The effect of nanofluid temperature on the nanofluid properties is measured in the range from $10^{\circ} \mathrm{C}$ to $90^{\circ} \mathrm{C}$. The data gained discovered that the copper nanoparticle completely covered by a layer of polyaniline with different thickness and the particle size distributed around $21.42 \mathrm{~nm}$. The thermal conductivity ratio of the Copper-Polyaniline nanocomposites water nanofluid increases $107 \%$ at nanofluid temperature of $10^{\circ} \mathrm{C}$ and $159 \%$ at $90^{\circ} \mathrm{C}$ for a volume fraction of $1.0 \%$. The Cu-PAni nanocomposite can be used as a potential material for thermal conductivity enhancement of water based nanofluid.
\end{abstract}

\section{KEYWORDS}

Nanofluids, Copper-Polyaniline, Nanocomposites nanoparticles, Thermal conductivity, Heat transfer enhancement, Transient hot-wire (THW).

Cyclotron Facility, NRC, Atomic Energy Authority, Cairo, Egypt.

Nuclear Reactors Department, NRC, Atomic Energy Authority, Egypt.

Second Research Reactor, NRC, Atomic Energy Authority, Egypt.

Corosponding Author: Salem M. Abdel-Samad, E-mail:

salem_abdelsamad@yahoo.com 


\section{NOMENCLATURE}

$\mathrm{K}=$ Thermal conductivity, $\mathrm{W} / \mathrm{m} . \mathrm{K}$

$\mathrm{q}=$ Heat rate, $\mathrm{W} \cdot \mathrm{m}^{-1}$

$\mathrm{T}=$ Temperature, ${ }^{\circ} \mathrm{C}$

$\mathrm{t}=$ time, $\mathrm{s}$

$E_{g}=$ optical band gap energy, eV

$\mathrm{h}=$ Blank constant,
Greek symbol

$\alpha$ : absorption

coefficient

$\mathrm{Y}$ : frequency

\section{Subscripts}

bf: Base fluid

nf: Nanofluid

$\mathrm{np}$ : Nanoparticles

\section{INTRODUCTION}

Nanotechnology and nanomaterials are extensively used in several applications, for example heat transfer, solar energy, medical applications, micromechanics and instrumentation [1-3]. A nanofluid is a type of colloid solutions produced by disbanding nanoparticles in a base fluid such as water alcohol [4]. These nanofluids have super properties from thermosphysical point of view, for instant, thermal conductivity, convective heat transfer coefficients, thermal diffusivity, and specific heat capacity [5]. Nanofluids have superiot stability, high thermal conductivity, low clogging problem and less pressure drop. With enhanced heat transfer characteristics, the size of the system can also be reduced $[6,7]$.

Copper powder is extensively used in many sides such as microelectronics for wiring, electromagnetic interference (EMI) shielding, electrostatic dissipation, enhancement of heat transfer of nanofluids, etc, [8-10]. Copper based nanofluids are widely used in industrial applications as coolants [11]. Polyaniline with metals as nanocomposite material has been syntherized by different methods and was used it in various applications. Anjali et al., [12] has prepared Cu-PAni and used it as a catalyst in the wacker oxidation reaction. Chew et al., [13] has been synthesized dodecyl benzene sulfonic acid-doped polyaniline nanoparticles with an average size of 20-30 nm using direct micelle polymerization. Furthermore, they were used it in water based nanofluid for thermal conductivity and specific heat capacity enhancement. PAni turn out to be conductive through doping. Han et al., [14] successfully synthesized dodecylbenzenesulfonic acid (DBSA)-doped PAni nanoparticles with an average size of 20-30 nm using direct micelle polymerization. Han et al., [15] produced uniform needle shape of DBSA-doped PAni nanoparticles using iso-octane as continuous phase. In addition, the DBSA-doped PAni nanoparticleshas been synthesized of in hexane using one-step reverse micelle polymerization [16].

The effect of nanoparticles volume fraction of alumina $\left(\mathrm{Al}_{2} \mathrm{O}_{3}\right)$ and copper oxide $(\mathrm{CuO})$ in water base nanofluids on the heat transfer characteristic has been studied [17-18]. The thermal conductivity inhancment of $\mathrm{Al}_{2} \mathrm{O}_{3}(28 \mathrm{~nm})$ and $\mathrm{CuO}(23 \mathrm{~nm})$ nanofluids has been observed. $\mathrm{Al}_{2} \mathrm{O}_{3}$ /water nanofluid, thermal conductivity improvement of $30 \%$ was achieved for water and ethylene glycol-based nanofluids. Srinivas and Vinod [19] measured the effective thermal conductivity ( $k_{\text {eff }}$ ) of nanofluids $\left(\mathrm{Al}_{2} \mathrm{O}_{3}\right.$ /water, $\mathrm{CuO} /$ water and $\mathrm{TiO}_{2}$ /water) at various temperatures $(40,45$, 50 , and $\left.60^{\circ} \mathrm{C}\right)$ and for five nanoparticle weight concentrations $(0.3,0.6,1,1.5$, and 2 wt. \%). They found that the effective thermal conductivity increased with increasing the concentration and temperature for the three nanofluids. They observed that 
$\mathrm{CuO} /$ water nanofluid has the highest effective thermal conductivity which increased by $10.2 \%$ when compared to water.

Polyaniline have been exhibited to be excellent hosts for catching nanoparticles of metals because of their ability to act as stabilizers or surface capping agents [20]. It terminates the growth of nanoparticles by controlling the nucleation and give uniform distribution of nanoparticles surrounded by PAni [21, 22]. Polyaniline nanoparticles have high thermal and chemical stability within the conductive form [23]. It is low production costs, and it can also be easily doped with inorganic and organic acids [24]. The nanoparticles like copper, silver, gold, and titanium provide a very exciting research field of nanofuides and potential uses in technological applications due to their extraordinary properties [25-27]. Copper-Polyaniline nanocomposite (Cu-PAni) in water based nanofluid is a good heat transfer medium to improve the heat transfer for cooling the very narrow channels and the extremely sensitive parts in the cyclotron accelerator like the two dees, the radio frequency and the ion source. Also an interesting application is to use Copper-Polyaniline nanocomposites/water nanofluid for cooling the high temperature components in the research reactors. No considerable studies have been done for Copper-Polyaniline nanocomposites/water nanofluid in the temperature range from $10{ }^{\circ} \mathrm{C}$ to $90{ }^{\circ} \mathrm{C}$ at volume fraction from $0.2 \%$ to $1.0 \%$.

In the present work we have been synthesized a Copper-Polyaniline nanocomposite (Cu-PAni) by gamma radiolysis method. We inspected the nanoparticles by analytical techniques like SEM, TEM, and XRD. Then we have dispersed the nanocomposite in distalled water at different nanofluids volume fractions of $0.2 \%, 0.4 \%, 0.6 \%, 0.8 \%$ and $1.0 \%$. The thermal conductivity of the nanofluids is measured in the range from $10^{\circ} \mathrm{C}$ to $90^{\circ} \mathrm{C}$.

\section{MATERIALS AND METHODS}

\section{Synthesis of Copper-Polyaniline Nanocomposite}

Reference standard copper solution (for ICP) was used as a source of copper and was obtained from AccuTrace Reference Standard, (USA). Aniline monomer (99.5\%), hydrochloric acid, ammonium per sulfate [APS, $(\mathrm{NH} 4)_{2} \mathrm{~S}_{2} \mathrm{O}_{8}$ ], and other organic solvents were obtained from Aldrich as reagent grade and were used as received. A typical in-situ chemical radiation-induced polymerization method for the Cu-PAni nanocomposites was carried out as follows; $375 \mathrm{~mL}$ of distilled water and 50 $\mathrm{mL}$ of 2-propanol solution containing $50 \mathrm{~mL}$ of copper standard was added to a 1000$\mathrm{mL}$ double-necked round-bottomed flask equipped with a magnetic Tefloncoated stirrer. The above mixture dispersed using sonicator for $60 \mathrm{~min}$ at ambient temperature. Aniline monomer $(1.5 \mathrm{~mL})$ with $150 \mathrm{~mL}$ of distilled water was added to the above solution and a colloidal suspension was obtained. Then, $150 \mathrm{~mL}$ of distilled water solution containing APS (2 g) was added dropwise, in small portions, to the suspension in a two-necked flask, with constant sonication, and a black solution was obtained. After removing oxygen by bubbling with pure argon gas for 30 min the solution was irradiated by ${ }^{60} \mathrm{Co}$ y-ray source $\left({ }^{60} \mathrm{Co}\right.$ Gamma-ray Irradiator) at dose of 10 kGy. The resultant Cu-PAni powder was carefully washed using centrifugation with methanol and distilled water until the filtrate was colorless. The obtained CuPAni (black powder) was dried under a vacuum dryer at room temperature for $24 \mathrm{~h}$. 
The PAni powders were synthesized using a similar method and the same mole ratios of monomer in absence of copper solution. Similar procedure for the preparation of $\mathrm{Ag}-\mathrm{PAni}$ is in ref. [28].

Cu-PAni powder nanoparticles with different weight concentrations were dispersed in distilled water as a base fluid. The volume concentrations of synthesized nanoparticles in water as base fluid were $0.2 \%, 0.4 \%, 0.6 \%, 0.8 \%$ and $1.0 \%$. The samples were placed on a magnetic stirrer for $30 \mathrm{~min}$, then in the ultrasonic bath at $70{ }^{\circ} \mathrm{C}$ for 1 hour to break down the agglomerations.

\section{Characterization of Copper Polyaniline Nanocomposites}

\section{Morphology and structure}

The morphology of the Cu-PAni nanocomposites was studied using scanning electron microscope (SEM) model no. JEOL JSM 5600 LV, made in USA and high resolution transmission electron microscopy (HR-TEM) model JEOL JEM-1230.

Figure $1(a, b)$ shows the SEM images of Cu-PAni nanocomposite at a magnification of $300 \mathrm{X}$ and $1000 \mathrm{X}$. It is seen that some of smaller particles stick on the larger particles. Moreover, the surface of copper particles is completely covered by polyaniline. Figure 2 shows that the (HR-TEM) of Cu-PAni nanocomposite recorded at $200 \mathrm{~nm}$. The images showed that there was not any significant interaction observed between the PAni and $\mathrm{Cu}$. The surface of granular metallic copper is completely coated by the PAni layers. Also, the inner part (core) is mainly copper metal, and the outer coated surface (shell) is polyaniline with variable thicknesses. On the other hand, it is also observed that the particle size of Cu-PAni nanocomposite is ranged from 13.68 to $29.16 \mathrm{~nm}$. On the other hand,. Similar results were obtained in ref. [29].

\section{FT-IR studies}

The FTIR spectra of the pure PAni and Cu-PAni nanocomposite are shown in Fig. 3. As can be seen, in PAni spectrum (a), the bands appeared at 1580 and $1507 \mathrm{~cm}^{-1}$ are characteristic to $\mathrm{C}=\mathrm{C}$ stretching band of the quinoid and benzenoid rings. The peaks appeared at 1298 and $740 \mathrm{~cm}^{-1}$ may be attributed to the $\mathrm{C}-\mathrm{N}$ stretching of the secondary aromatic amine and an aromatic $\mathrm{C}-\mathrm{H}$ out-of- plane bending vibration, respectively. The relatively small peak at $3265 \mathrm{~cm}^{-1}$ can be related to the $\mathrm{N}-\mathrm{H}$ stretching vibration mode. In the region of $1000-1174 \mathrm{~cm}^{-1}$, aromatic $\mathrm{C}-\mathrm{H}$ in plane bending modes are usually observed. Furthermore, there is a higher peak at 3250 $\mathrm{cm}^{-1}$, which is a result from crosslinking moieties. From the above observations, it can be indicated that the formed material is polyaniline. The data of PAni is in good agreements with previously reported results [30]. The spectrum (b) represents the copper polyaniline (PAni) and the peaks locations related to the corresponding chemical bonds, which are in good agreement with the reported works [31]. All characteristic bands of polyaniline are present between 700 and $1592 \mathrm{~cm}^{-1}$ and these are all found in Cu-PAni nanocomposite powders with small shift; the intensity of the some peaks was decreased due to presence of nanocopper.

\section{XRD analysis}

Figure 4 is the X-ray diffractions (XRD) patterns of the Cu-PAni nanocomposite

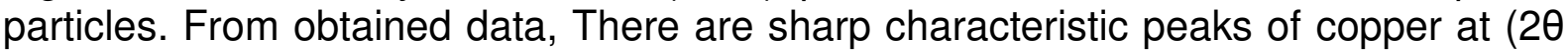
$=43.04^{\circ}, 50.36^{\circ}$ and $74.10^{\circ}$ ), assigned as (111), (200), and (220) respectively as 
matched in ref. [32]. On the other hand, there is a weak characteristic peak of polyaniline (PAni) can be observed at $2 \theta=24.88$ in the pattern too. The data of XRD confirmed the presence of Cu-PAni nanocomposite that was prepared by gamma radiolysis method and also, there is no any amount of copper oxide in the sample. Similar XRD results of Cu-PAni nanocomposites with different preparation methods are in ref. [29].

\section{TGA and DTA analysis}

Thermal stability testing of Cu-PAni powder was conducted using Shimadzu DTATGA system of type DTA-TGA-60, Japan with platinum crucible and alumina powder reference. Figure 5 shows a TGA-DTA curve of Cu-PAni nanocomposites upon heating in a nitrogen atmosphere at a rate of $\left(20^{\circ} \mathrm{C} / \mathrm{min}\right)$ with temperature range from 0 to $800{ }^{\circ} \mathrm{C}$. According to TGA-DTA data, the Cu-PAni nanocomposites undergoes three stages of degradation: (a) the first weight loss was $5.52 \%$ and may be related to the loss of planar water (b) the second weight loss was $61.3 \%$ due to degradation of polymeric chains, (c) the last weight loss was $25 \%$ and may be related to decomposition of polyaniline backbone and benzene ring-opening [33]. The results obtained from TGA confirmed that the Cu-PAni nanocomposite is very stable under the temperature range of the thermal conductivity experiments in this work.

\section{UV-Visible absorption study}

Ultraviolet and visible spectra were recorded from the synthesized PAni and CuPAni using Lamda-25; PerkinElmer; Waltham, Massachusetts and scanning the spectra between 200 and $800 \mathrm{~nm}$. Ethanol was used as a solvent during the analysis. Figure 6 shows the UV-Visible pattern of PAni and Cu-PAni. The spectrum of PAni has 2 peaks, one at $243 \mathrm{~nm}$ and other one at $393 \mathrm{~nm}$. The first peak may be attributed to the presence of aniline moiety and the other obtained peak may be related to the presence of benzenoid group and the lone pair of electrons on nitrogen atom. On the other hand, the spectra of Cu-PAni nanocomposite show a new peak at $553 \mathrm{~nm}$ and a blue shift from 393 to $363 \mathrm{~nm}$ of the exciting peak in the polyaniline. The optical band gap of PAni and Cu- PAni was investigated by Tauc's relationship [34] as represented in the following equation:

$$
\alpha h \gamma=A\left(h \gamma-E_{g}\right)^{n}
$$

where $(\alpha)$ is the absorption coefficient, $(A)$ is constant, $\left(E_{g}\right)$ is the optical band gap of studied material and the values of $(n)$ depend upon the nature of electronic transmission; it is equal to (1/2) in case of direct allowed, (3/2) for direct forbidden transitions and (2) for indirect allowed transition. The kind of transition is confirmed by determining the power $(n)$ that showed a value of $n=(1 / 2)$ revealing to direct allowed transition $[35,36]$.

\section{THERMAL CONDUCTIVITY MEASURMENTS OF COPPER-POLYANILINE WATER BASED NANOFLUID}

The thermal conductivity of the nanofluids were measured based on the transient hot wire (THW) technique [37-38]. The experimental setup as shown in Figure 7 for the nanofluid thermal conductivity is explained in our earlier work [39]. It include : (1) Power supply model (CIC - PS-1220 and EZ Digital GP-4303D, Korea); (2) Water bath with constant temperature which has temperature sensor and thermostat 
control; (3) A glass test cell $50 \mathrm{ml}$ enclosed the nanofluids used in the experiments with isolated electric heater made of tungsten and thermocouple; and (4) Data acquisition model: (Pico, USB TC-08 thermocouple data logger, UK.) temperature measurement with 8 direct thermocouple inputs. The accuracy of the TC-08 is $( \pm 0.2$ $\left.{ }^{\circ} \mathrm{C}\right)$. Laptop connected to the data logger through USB. The constant temperature water bath is heated by a tungsten heater and can be controlled via thermostat and thermocouple connected to the computer to control the temperature of the bath at the performed temperature within $\pm 0.05^{\circ} \mathrm{C}$ through the experiments. The glass test cell enclosing the nanofluid, metallic tungsten wire was used as a heat source and a thermocouple was used as a thermometer. The test cell is placed inside the constant temperature bath.During the short measurement interval of 2 to 5 seconds, natural convection will not effect on the results accuracy. At a measuring time $t_{1}$ and $t_{2}$, the nanofluid temperatures are $T_{1}$ and $T_{2}$, then the thermal conductivity $\left(k_{n f}\right)$ is determined from the relationship:

$$
k_{n f}=\frac{q}{4 \pi} \frac{\ln \left(t_{2} / t_{1}\right)}{\left(T_{2}-T_{1}\right)}
$$

A test has been done for calibration of distilled water which used as a base fluid in temperature ranges of $10^{\circ} \mathrm{C}$ to $90^{\circ} \mathrm{C}$. The tested copper polyaniline /water nanofluid in the test section is immersed in the water bath and stay for about 5 minutes that the temperature of the nanofluid is become stable with the bath. The measurements are conducted and the readings are recorded in second as a time step. The calculation is carried out for a time length less than 5 seconds in order to eliminate natural convection of the nanofluid. The nanofluid temperature measurements ranging from $10^{\circ} \mathrm{C}$ to $90^{\circ} \mathrm{C}$ are taken. These temperature measurement procedures are repeated for the copper polyaniline /water nanofluid at different volume fraction.

Figure 8 depicts the thermal conductivity of 13.68 to $29.16 \mathrm{~nm}$ Cu-PAni nanocomposite-water nanofluid at different volume fraction $(0.2 \%, 0.4 \%, 0.6 \%, 0.8 \%$ and $1.0 \%)$ for different operating temperature ranged from $10(\circ \mathrm{C})$ to $90\left({ }^{\circ} \mathrm{C}\right)$. Significant improvement can be seen for the thermal conductivity of Cu-PANI nanocomposite-water nanofluid due to the presence of nanocomposites. The improvement increases with increasing of the nanocomposites volume fraction and the operating temperature. The thermal conductivity of the thin polyaniline is very low $(0.2 \mathrm{~W} / \mathrm{m} . \mathrm{K})$, [18], comparable with the thermal conductivity of copper particles is very high $(401 \mathrm{~W} / \mathrm{mK}),[40]$, the thin layer of polyaniline prevents the copper from oxidation and transform to copper oxide $(\mathrm{CuO})$ which it's thermal conductivity is $20 \mathrm{~W} / \mathrm{m} . \mathrm{K}$ which has been investigated by many researchers [41].

The thermal conductivity of Copper-Polyaniline nanocomposites/water based nanofluid is $1.21 \mathrm{~W} / \mathrm{m} . \mathrm{K}$ at $10^{\circ} \mathrm{C}$ and $1.74 \mathrm{~W} / \mathrm{m} . \mathrm{K}$ at $90^{\circ} \mathrm{C}$ for $1.0 \%$ volume fraction compared with the distilled water, which is $0.5833 \mathrm{~W} / \mathrm{m} . \mathrm{K}$ to $0.6724 \mathrm{~W} / \mathrm{m} . \mathrm{K}$ respectively.

Figure 9 illustrates the relation between the thermal conductivity ratio of nanofluid to water base fluid $\left(\mathrm{K}_{\mathrm{nf}} / \mathrm{K}_{\mathrm{bf}}\right)$ and the operating temperature for different volume fractions. As seen from the figure, the thermal conductivity increases with the volume fraction increasing for the same operating temperature due to the higher concentration of the Cu-PAni nanocomposite which results in large surface area of the nanoparticles which affect on heat transfer enhancement. The thermal conductivity ratio of 
nanofluid to water base fluid $\left(\mathrm{K}_{\mathrm{nf}} / \mathrm{K}_{\mathrm{bf}}\right)$ is 2.1 at $10^{\circ} \mathrm{C}$ and 2.6 at $90^{\circ} \mathrm{C}$ for $1.0 \%$ volume fraction while it is 1.1 at $10^{\circ} \mathrm{C}$ and 1.7 at $90^{\circ} \mathrm{C}$ for $0.2 \%$ volume fraction.

\section{CONCLUSION}

A new method has been used for synthesize copper polyaniline (Cu-PAni) nanocomposite. The structure of obtained Cu-PAni nanocomposite was characterized using HR-TEM, SEM, FTIR, XRD and TGA-DTA. The obtained CuPAni nanocomposite has different particle size distributed around $21.42 \mathrm{~nm}$. CopperPolyaniline nanocomposite was dispersed in distilled water nanofluid with volume fraction varies from $0.2 \%$ to $1.0 \%$. The nanofluid at temperature ranges from $10^{\circ} \mathrm{C}$ to $90^{\circ} \mathrm{C}$ has been tested. The thermal conductivity of nanofluids has been measured by modified transient hot wire technique. The thermal conductivity ratio of the CopperPolyaniline nanocomposites water nanofluid increases $107 \%$ at nanofluid temperature of $10^{\circ} \mathrm{C}$ and $159 \%$ at $90^{\circ} \mathrm{C}$ for a volume fraction of $1.0 \%$. The results show that as the nanofluid volume fraction and temperature increase the thermal conductivity and the enhancement ratio also increase. The Cu-PAni nanocomposite can be used as a potential material for thermal conductivity enhancement of water based nanofluid.

\section{REFERENCES}

[1] S. M. Murshed, K.C Leong and C. Yang "Thermophysical and electrokinetic properties of nanofluids-A critical review", Appl. Therm. Eng. Vol. 28, pp. 2109-2125 (2008).

[2] R. Saidur, K. Leong, and H. A. Mohammad "A review on applications and challenges of nanofluids", Renew. Sustain. Energy Rev.Vol. 15, pp.1646-1668 (2011).

[3] O. Mahian, A. Kianifar, S. A. Kalogirou, I. Pop and S. Wongwises "A review of the applications of nanofluids in solar energy", Int. J. Heat Mass Transf., Vol. 57, pp.582-594 (2013).

[4] S.U.S.Choi and J.A. Eastman "Enhancing thermal conductivity of fluids with nanoparticles", In Proceedings of the ASME International Mechanical Engineering Congress \& Exposition, pp. 99-105. San Francisco, CA, USA, November (1995).

[5] W. Xu and H. Xie "A review on nanofluids Preparation, stability mechanisms, and applications", J. Nanomater. doi:10.1155/2012/435873 pp. 1-18 (2012).

[6] Li. Y, Zhou J., Tung S., Schneider E. and Xi S "A review on development of nanofluid preparation and characterization", Powder Technol., 196, pp. 89-101 (2009).

[7] Ghadimi, A.; Saidur, R.; Metselaar, H.S.C, "A review of nanofluid stability properties and characterization in stationary conditions", Int. J. Heat Mass Transf., 54, pp. 4051-4068 (2011).

[8] Sonal Patil; Sainkar, S.R.; Patil, P.P. Poly "(o-anisidine) coatings on copper: synthesis, characterization and evaluation of corrosion protection performance", Appl. Surf. Sci., 225, pp. 204-216 (2004).

[9] Pavlović, M.G.; Pavlović, Lj. J.; Doroslovački, I. D.; Nikolić, N.D., "The effect of benzoic acid on the corrosion and stabilisation of electrodeposited copper powder", Hydrometallurgy, 73, pp.155-162 (2004). 
[10] Manimaran R.; Palaniradja K.; Alagumurthi N.; Sendhilnathan S.; Hussain J. "Preparation and characterization of copper oxide nanofluid for heat transfer applications", 4, pp. 163-167(1014).

[11] Anand, S. K., Meenakshi, K. S., Narashimhan, B. R. V., Srikanth, S., Arthanareeswaran, G. "Synthesis and Characterization of Copper Nanofluid by a Novel One-Step Method", Materials Chemistry and Physics, 11 3,pp. 57-62 (2009).

[12] Anjali A. Athawale; Bhagwat S. V. "Synthesis and Characterization of Novel Copper/Polyaniline Nanocomposite and Application as a Catalyst in the Wacker Oxidation Reaction", Journal of Applied Polymer Science, 89, pp. 24122417(2003).

[13] Tze Siong Chew, Rusli Daik, and Muhammad Azmi Abdul Hamid, "Thermal Conductivity and Specific Heat Capacity of Dodecylbenzenesulfonic AcidDoped Polyaniline Particles-Water Based Nanofluid", Polymers, 7, pp.12211231(2015).

[14] Han, M.G.; Cho, S.K.; Oh, S.G.; Im, S.S., "Preparation and characterization of polyaniline nanoparticles synthesized from DBSA micellar solution", Synth. Metals, 126, pp. 53-60 (2002).

[15] Han, D.; Chu, Y.; Yang, L.; Liu, Y.; Lv, Z., "Reversed micelle polymerization: A new route for the synthesis of DBSA-polyaniline nanoparticles. Colloids Surfaces", A 2005, 259, 179-187.

[16] Han, Y.-G.; Kusunose, T.; Sekino, T.,"One-step reverse micelle polymerization of organic dispersible polyaniline nanoparticles", Synth. Metals 2009, 159, 123131.

[17] Patel, H.E.; Sundararajan, T.; Das, S.K. "An experimental investigation into the thermal conductivity enhancement in oxide and metallic nanofluids", J. Nanopart. Res., 2010, 12, 1015-2010.

[18] Usri, N.A.; Azmi, W.H.; Mamat, R.; Abdul Hamid, K.; Najafi, G., "Thermal conductivity enhancement of al2o3 nanofluid in ethylene glycol and water mixture", Energy Procedia, 2015, 79, 397-402.

[19] Srinivas, T.; Vinod, A.V. "The effective thermal conductivity of water based nanofluids at different temperatures", J. Test. Eval., 2016, 44, 280-289.

[20] Karim M. R.; Lim K. T.; Lee V; Bhuiyan T. I.; Kim H. J.; Park L. S.; Lee M. S., "Synthesis of Core-Shell Silver-Polyaniline Nanocomposites by Gamma Radiolysis Method", J Polym Sci Part A: Polym. Chem., 2007, 45, 5741-5747.

[21] Grubbs R. B. Hybrid metal-polymer composites from functional block copolymers. J Polym. Sci. Part A: Polym Chem 2005, 43, 4323-4336.

[22] Karim, M. R.; Lee, C. J.; Park, Y.-T.; Lee, M. S., "Synthesis and thermal stability studies of polyaniline/silver nanocomposite based on reduction of silver ions using polyaniline", Synth Met 2005, 151, 131-135.

[23] Heeger, A. J., "Semiconducting and Metallic Polymers: The Fourth Generation of Polymeric Materials", J Phys Chem B 2001, 105, 8475-8491.

[24] Hong, K. H.; Kang, T. J., "Development of Conducting Polyaniline/Poly(lactic acid) Nanofibers by Electrospinning", J Appl Polym Sci 2006, 99, 1277-1286.

[25] Garg, J.; Poudel, B.; Chiesa, M.; Gordon, J. B.; Ma, J. J.; Wang, J. B.; Ren, Z. F.; Kang, Y. T.; Ohtani, H.; Nanda, J.; McKinley, G. H. and Chen, G., "Enhanced thermal conductivity and viscosity of copper nanoparticles in ethylene glycol nanofluid", J Appl Phys, 2008, 103, 07430.

[26] Paul, G.; Pal, V.; Manna, I., "Thermo-physical property measurement of nanogold dispersed water based nanofluids prepared by chemical precipitation technique", J. Colloid and Interface Science 2010, 349, 434-437. 
[27] Sezer, Ö.; Sadık, K.; Almıla, G. Y., "Enhanced thermal conductivity of nanofluids: a state-of-the-art review", Microfluidics and Nanofluidics. 2010, 8, 145-170.

[28] Mohammad Rezaul Karim, Kwon Taek Lim, Chul Jae Lee, Md Tauhidul Islam Bhuiyan, Hee Jin Kim, Lee-Soon Park, Mu Sang Lee, "Synthesis of Core-Shell Silver-Polyaniline Nanocomposites by Gamma Radiolysis Method", Journal of Polymer Science: Part A: Polymer Chemistry, 2007, 45, 5741-5747.

[29] Yan-hui Guo, Bin-bo Jiang, Ji-zhong Chen, Shi-jie Zhang, "A catalytic oxidation approach to coat copper powder with polyaniline", Surf. Coat. Technol., 2007, 202, 555-558.

[30] Gok, A.; Sari, B.; Talu, M., "Synthesis and Characterization of Conducting Substituted Polyanilines", Synth Met 2004, 142, 41-48.

[31] Du, J.; Liu, Z.; Han, B.; Li, Z.; Zhang, J.; Huang, Y., "One-pot synthesis of the macroporous polyaniline microspheres and Ag/polyaniline core-shell particles. Microporous and Mesoporous", Mater 2005, 84, 254-260.

[32] Rittermeier, A.; Miao, S.; Schroter, M. K.; Zhang, X.; Maurits W. E.; Kundu, S.; Wang, Y.; Schimpf, Z.; Loffler, E.; Fischer R. A. and Muhler, M., "The formation of colloidal copper nanoparticles stabilized by zinc stearate: one-pot single-step synthesis and characterization of the core-shell particles", Phys. Chem. Chem. Phys., 2009, 11, 8358-8366

[33] TAUC, V.; MENTH, A., States in the Gap. Journal of Non-Crystalline Solids, 1972, 8-10, 569-585.

[34] Shaik k.Ahmmad, M.A. Samee, A. Edukondalu, Syed Rahman, "Physical and optical properties of zinc arsenic tellurite glasse"s, Results in Physics, 2012, 2, $175-181$.

[35] Nefzi, K.; Rabhi, A.; Kanzari, M. , "Investigation of physical properties and impedance spectroscopy study of Cu3SbS3 thin films", J Materials Science: Materials in Electronics, 2016, 27, 1888-1896.

[36] Kleinstreuer, C.; Feng, Y., "Experimental and theoretical studies of nanofluid thermal conductivity enhancement: a review", Nanoscale Research Letters. 2011, 6, 229-241.

[37] Buongiorno, J.; Venerusn, DC.; Prabhat, N., A benchmark, "Study on the thermal conductivity of nanofluids", J. Appl. Phys. 2009, 106, 094312-14.

[38] Yoo, D. H.; Hong, K. S.; Ysng, H. S., "Study of thermal conductivity of nanofluids for the applications of heat transfer fluids", Thermochim Acta. 2007, 455, 66-69.

[39] Abdel-Samad, S. M.; Fahmy, A. A,; Massoud, A. A. and Elbedwehy, A. M., "Experimental Investigation of $\mathrm{TiO}_{2}$-Water Nanofluids Thermal Conductivity Synthesized by Sol-Gel Technique", Current Nanoscience, 2017, 13, 1-9.

[40] Sigh, S.; Sharma, S.; Gangacharyulu, D., "Comparative study of various thermo-physical properties of metallic \& oxides nanofluids", Int. J. Eng. Sci. \& Res. Tech., 2015, 4, 797- 803.

[41] Liu, M. S; Lin,M. C.; Huang, I.-Te; Wang, W., "Enhancement of Thermal Conductivity with CuO for Nanofluids", Chem. Eng. Technol., 2006, 29,72-77. 

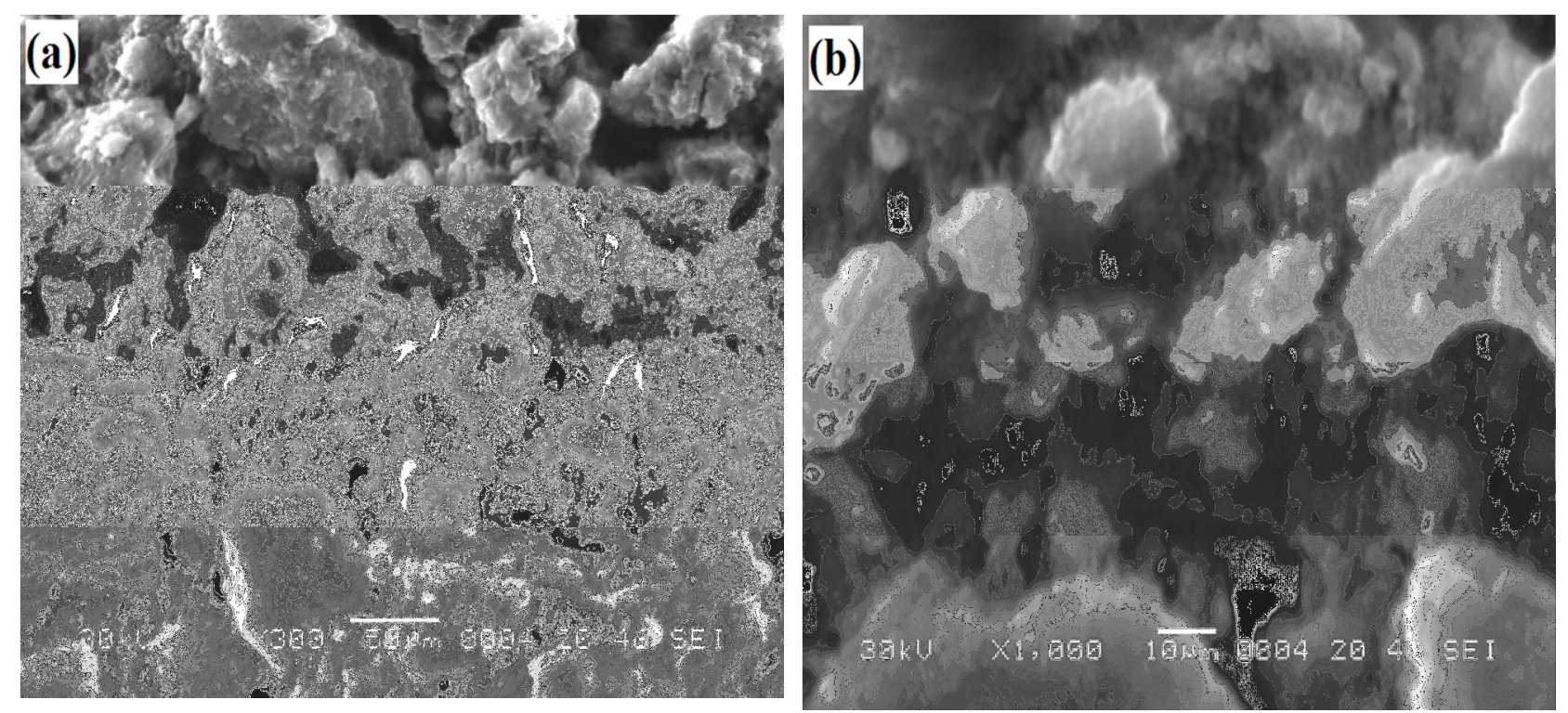

Fig.1. The SEM images of Cu-PAni nanocomposite at (a) 300X and (b) 1000X.

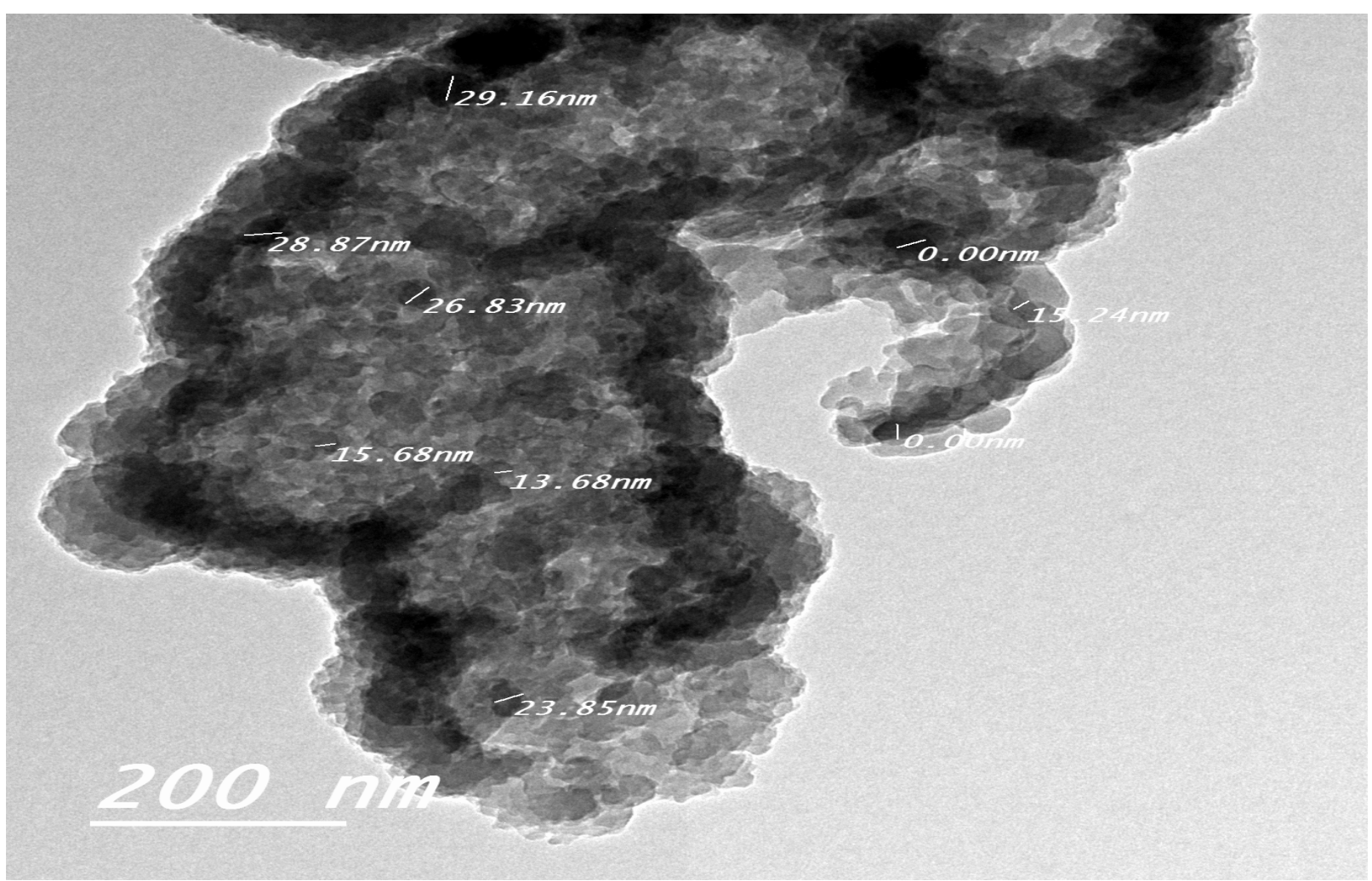

Fig.2. The HR-TEM of Cu-PAni nanocomposite. 


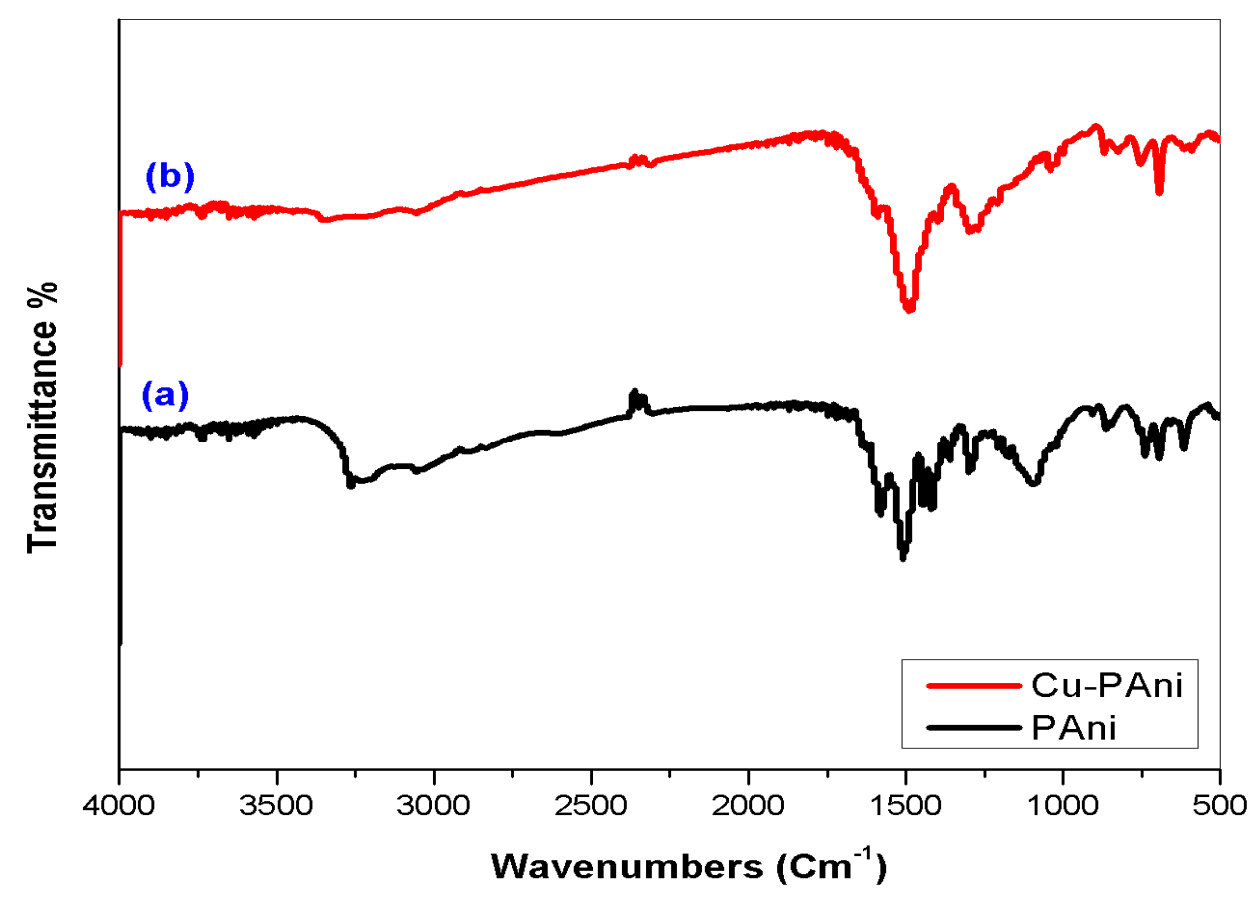

Fig.3. FTIR spectra of bulk PAni powder (a) and (b) Cu-PAni nanocomposites.

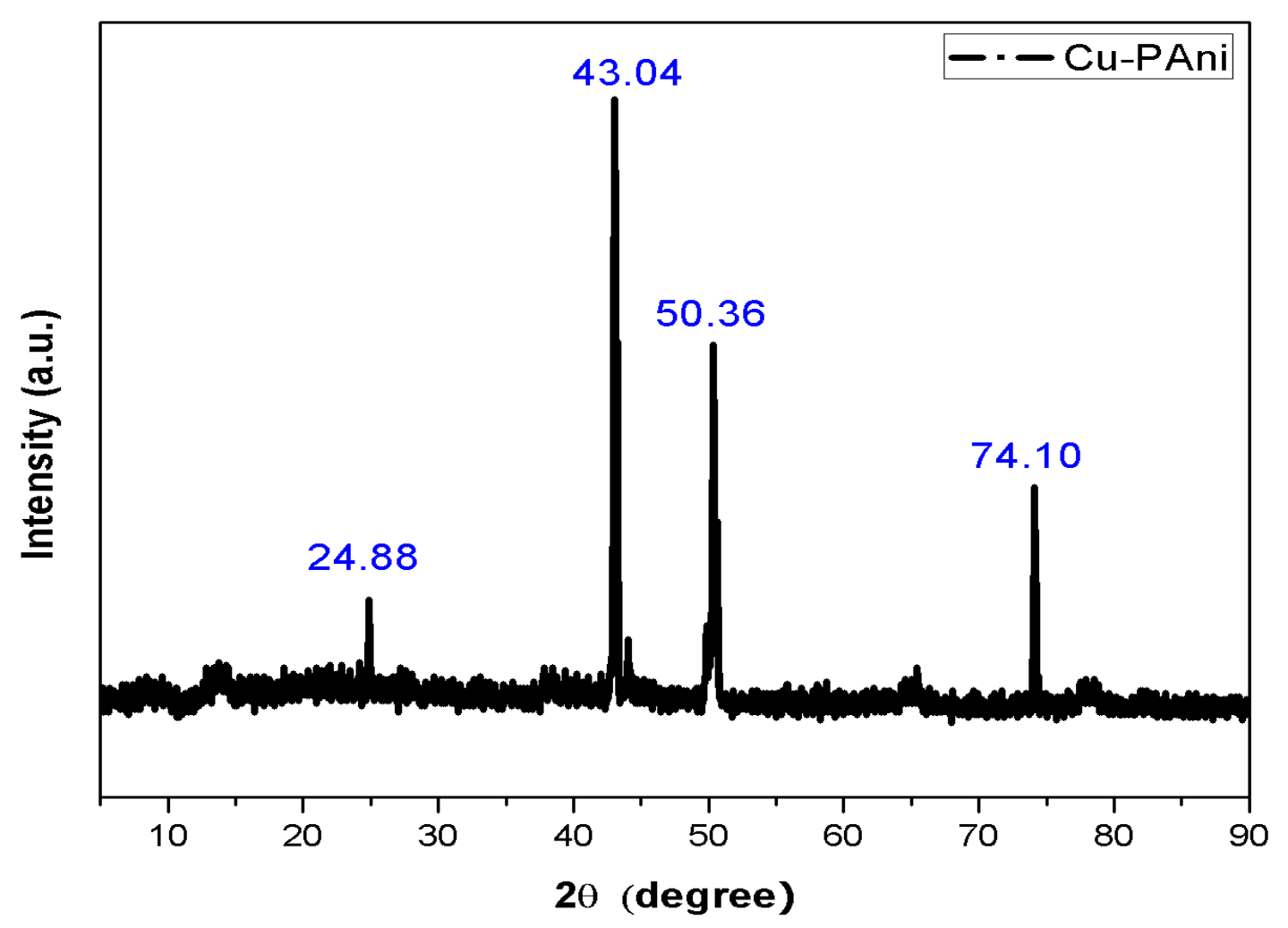

Fig.4. XRD patterns of Cu-PAni nanocomposites. 


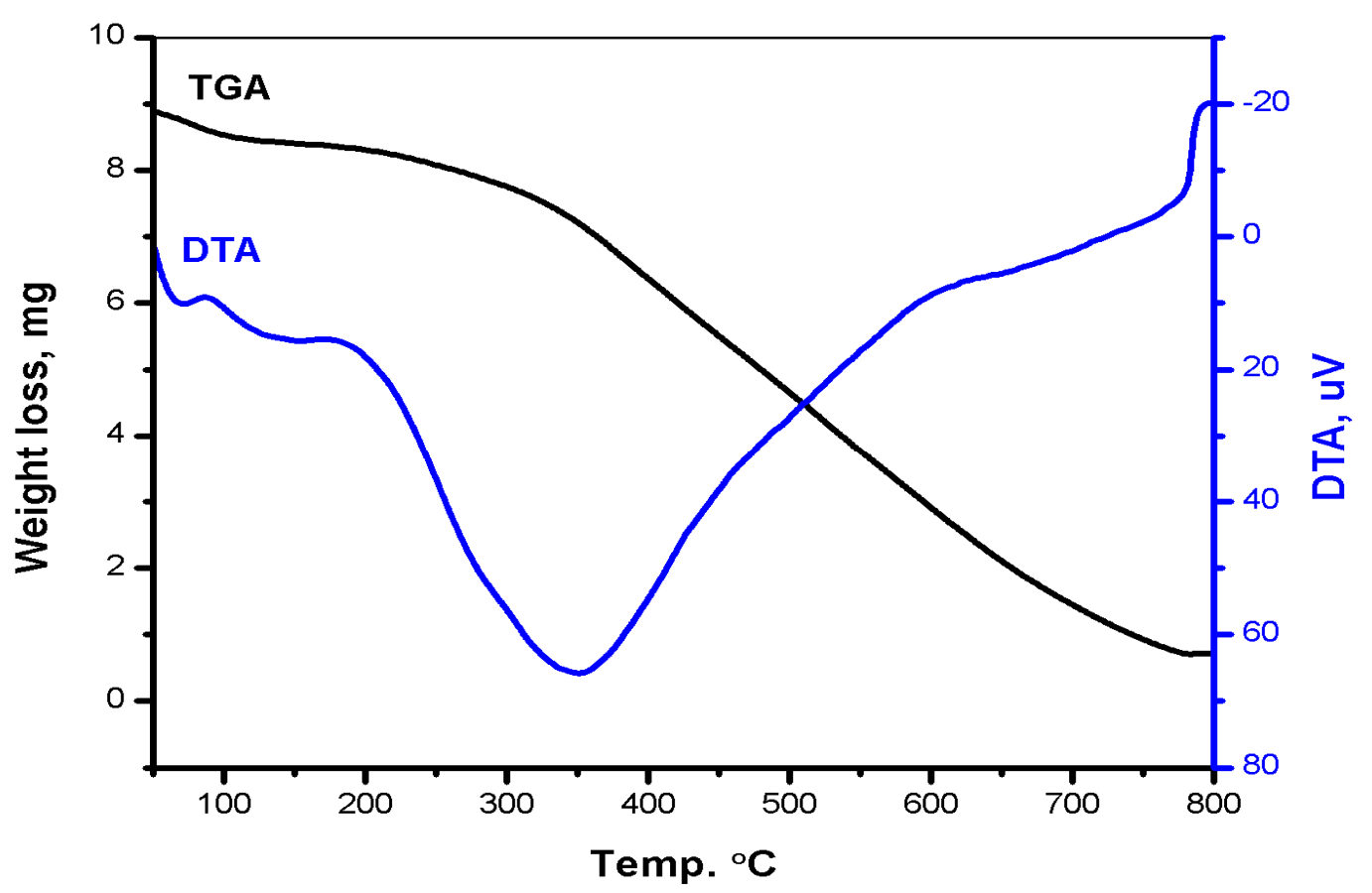

Fig.5. TGA-DTA curve of Cu-PAni nanocomposite under nitrogen atmosphere.

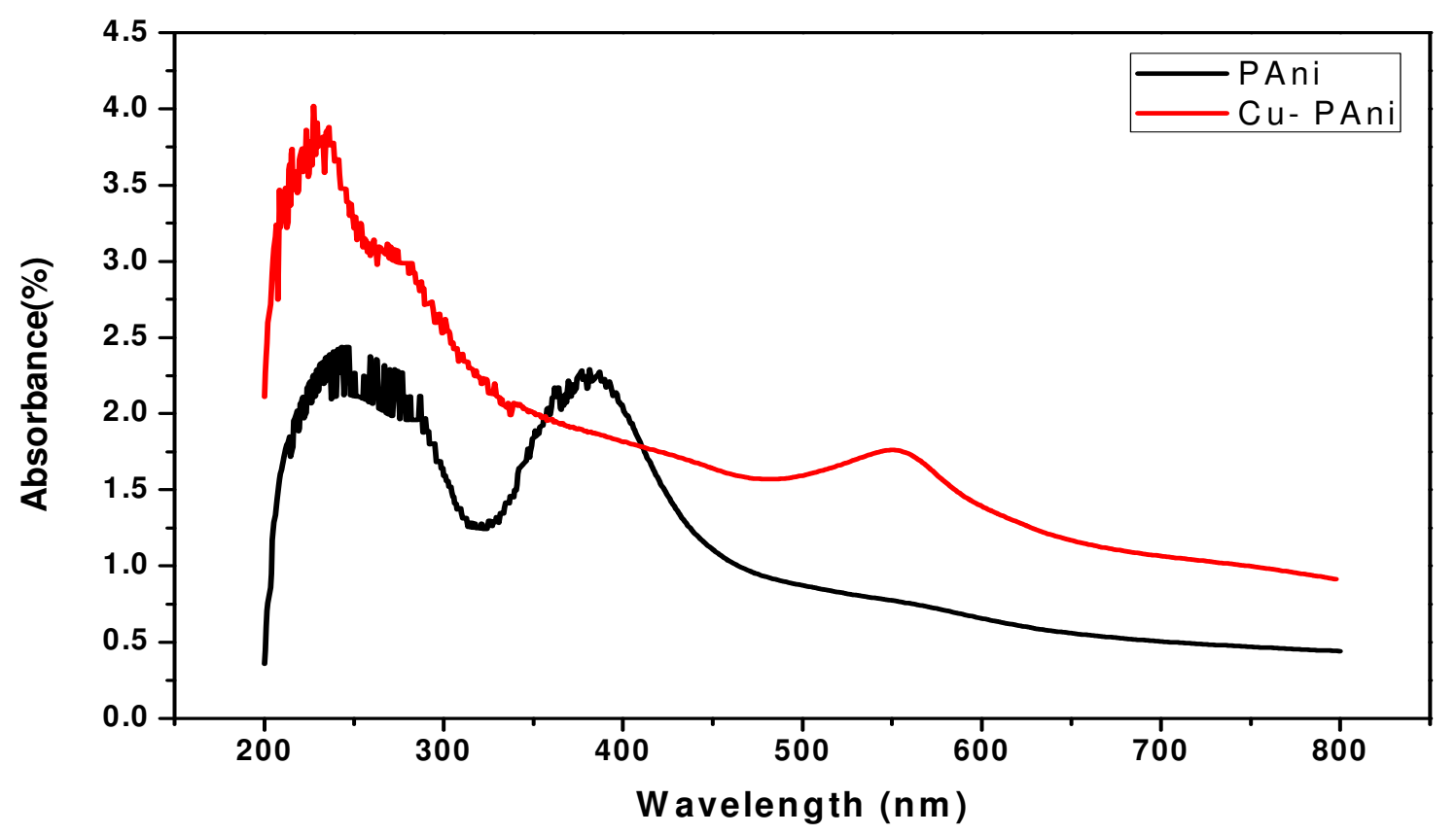

Fig.6. UV-visible spectra of PAni and Cu-PAni nanocomposites in ethanol solution. 


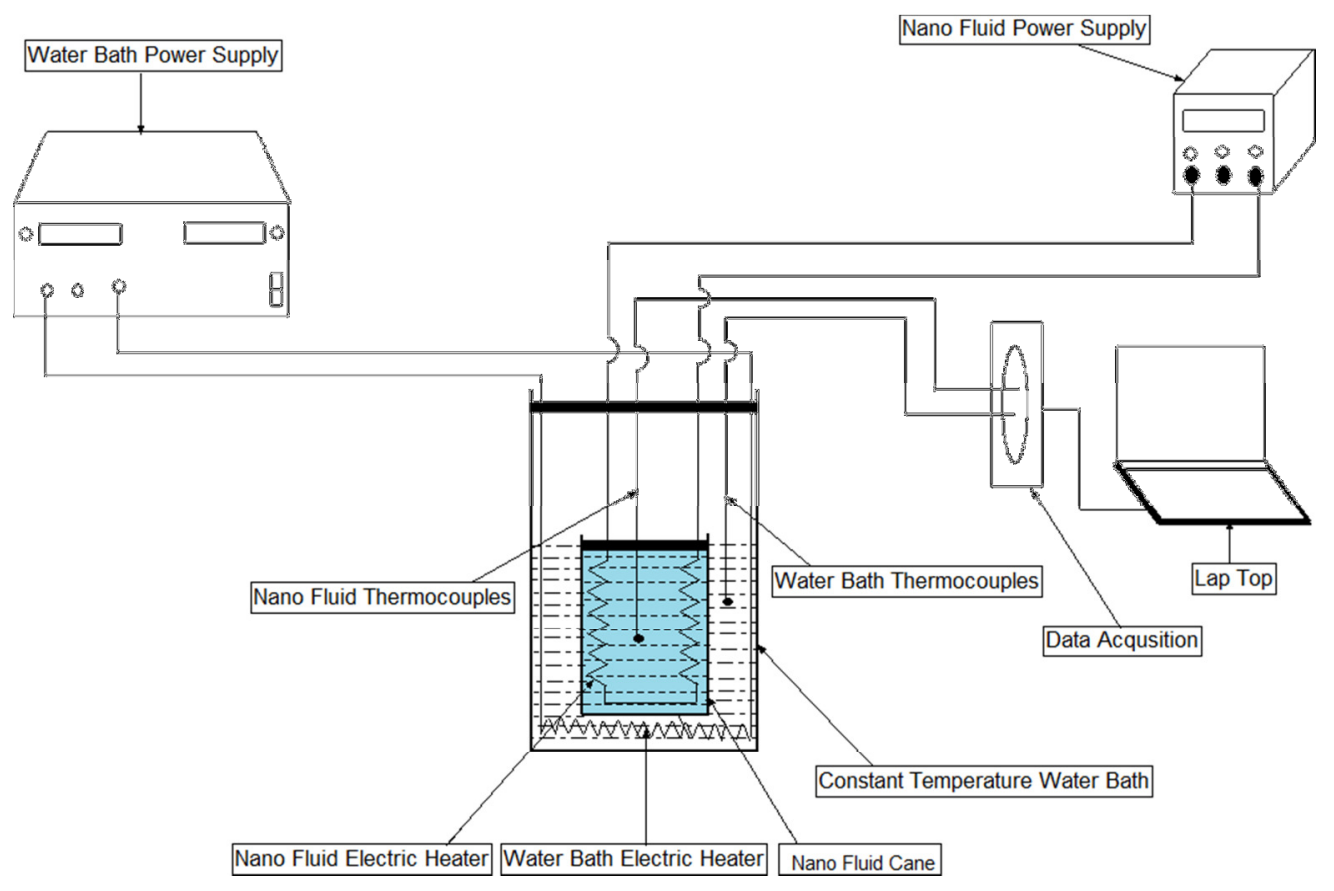

Fig. 7. Schematic diagram of the test section, water bath and nanofluid cane.

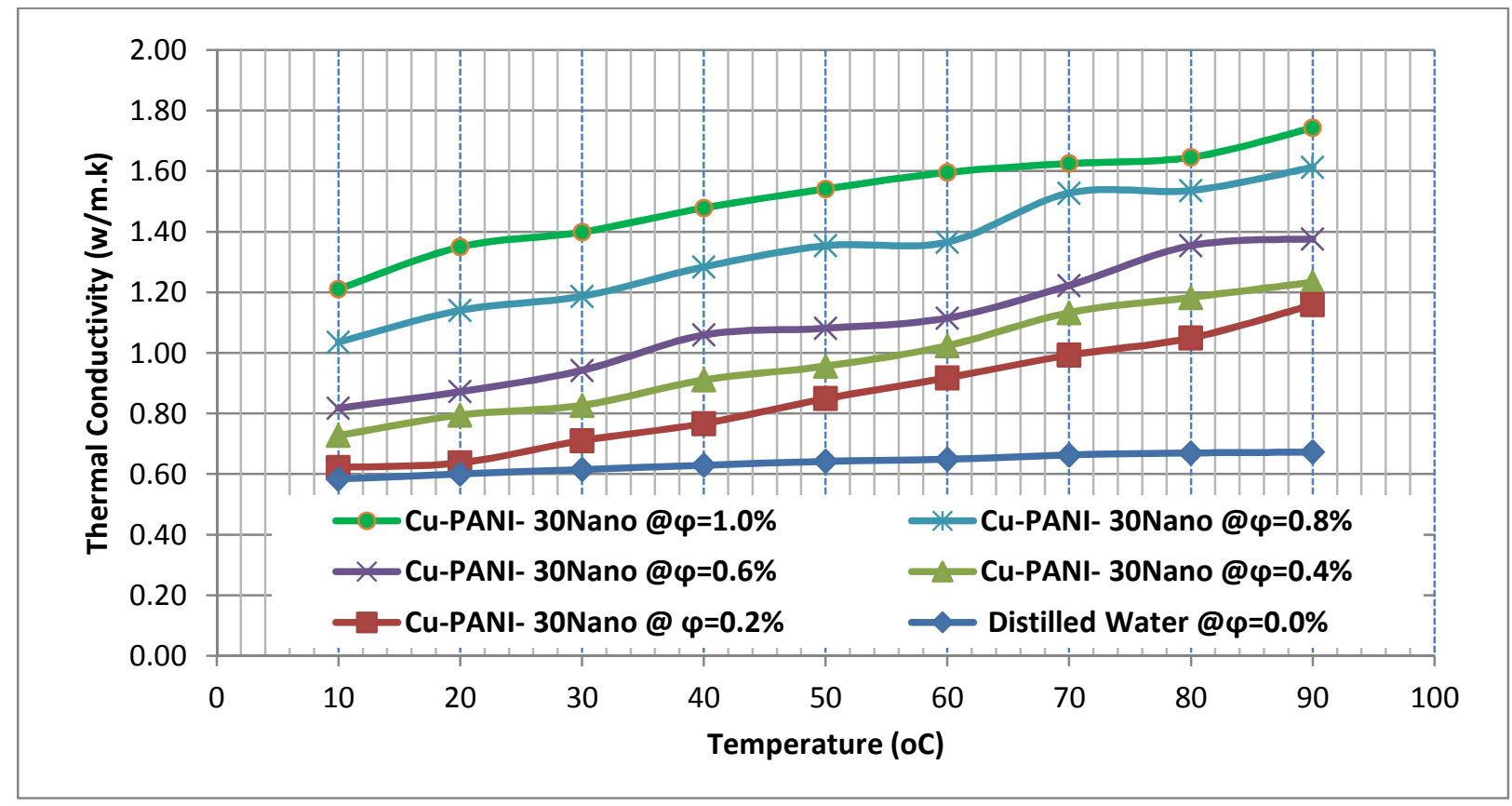

Fig. 8. The thermal conductivity of Copper-Polyaniline Nanocomposites-water nanofluid as a function of temperature at various values of particle volume fraction. 


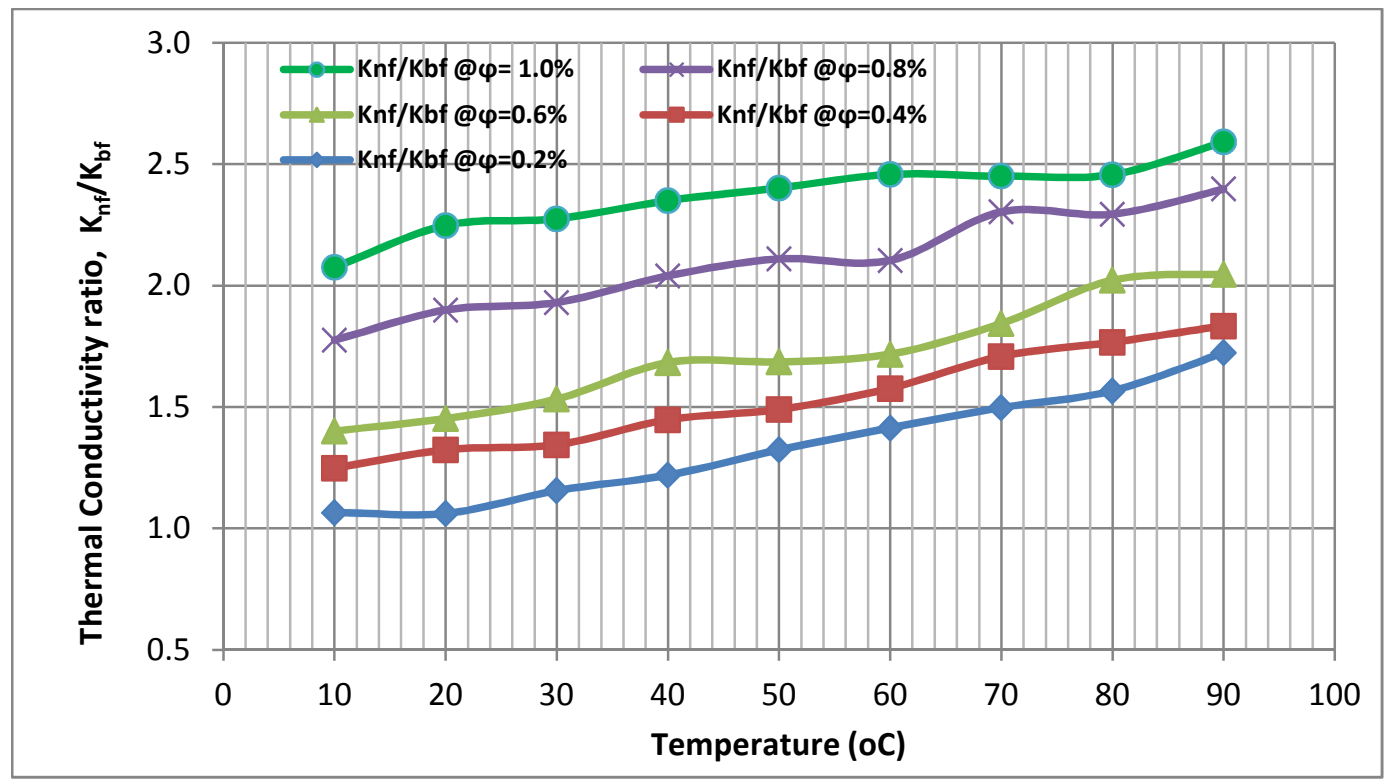

Fig. 9. The thermal conductivity ratio for Copper-Polyaniline nanocomposites -water nanofluid to that of the distilled water base fluid as a function of temperature at various volume fractions. 